University of Nebraska - Lincoln

DigitalCommons@University of Nebraska - Lincoln

Biological Systems Engineering: Papers and

Publications

Biological Systems Engineering

2020

\title{
Calibration of a common shortwave multispectral camera system for quantitative agricultural applications
}

\author{
J. Burdette Barker \\ University of Nebraska-Lincoln, burdette.barker@huskers.unl.edu \\ Wayne Woldt \\ University of Nebraska - Lincoln, wwoldt1@unl.edu \\ Brian Wardlow \\ University of Nebraska - Lincoln, bwardlow2@unl.edu \\ Christopher Michael Usher Neale \\ University of Nebraska-Lincoln, cneale@nebraska.edu \\ Mitchell S. Maguire \\ University of Nebraska-Lincoln, mitchmaguire2@gmail.com
}

See next page for additional authors

Follow this and additional works at: https://digitalcommons.unl.edu/biosysengfacpub

Part of the Bioresource and Agricultural Engineering Commons, Environmental Engineering Commons, and the Other Civil and Environmental Engineering Commons

Barker, J. Burdette; Woldt, Wayne; Wardlow, Brian; Neale, Christopher Michael Usher; Maguire, Mitchell S.; Leavitt, Bryan; and Heeren, Derek M., "Calibration of a common shortwave multispectral camera system for quantitative agricultural applications" (2020). Biological Systems Engineering: Papers and Publications. 667.

https://digitalcommons.unl.edu/biosysengfacpub/667

This Article is brought to you for free and open access by the Biological Systems Engineering at DigitalCommons@University of Nebraska - Lincoln. It has been accepted for inclusion in Biological Systems Engineering: Papers and Publications by an authorized administrator of DigitalCommons@University of Nebraska Lincoln. 


\section{Authors}

J. Burdette Barker, Wayne Woldt, Brian Wardlow, Christopher Michael Usher Neale, Mitchell S. Maguire, Bryan Leavitt, and Derek M. Heeren 


\title{
Calibration of a common shortwave multispectral camera system for quantitative agricultural applications
}

\author{
J. Burdette Barker, ${ }^{1,2,4}$ Wayne E. Woldt, ${ }^{2,3}$ \\ Brian D. Wardlow, ${ }^{3}$ Christopher M. U. Neale, ${ }^{2,4}$ \\ Mitchell S. Maguire, ${ }^{2}$ Bryan C. Leavitt, ${ }^{3}$ \\ and Derek M. Heeren ${ }^{2}$
}

1 Present Address: Natural Resources Consulting Engineers, Inc, 131 Lincoln Ave, Suite 300, Fort Collins, CO 80524, USA

2 Biological Systems Engineering Department, University of Nebraska-Lincoln, L.W. Chase Hall, 3605 Fair St, Lincoln, NE 68583, USA

3 School of Natural Resources, University of Nebraska-Lincoln, Hardin Hall, 3310 Holdrege St, Lincoln, NE 68583, USA

4 Daugherty Water for Food Global Institute at the University of Nebraska, 2021 Transformation Drive, Suite 3220, Lincoln, NE 68588, USA

ORCID

J. Burdette Barker http://orcid.org/0000-0002-5100-4971

Brian D. Wardlow http://orcid.org/0000-0002-4767-581X

Christopher M. U. Neale http://orcid.org/0000-0002-7199-6410

Derek M. Heeren http://orcid.org/0000-0002-0222-5516

\begin{abstract}
Unmanned aerial systems (UAS) for collecting multispectral imagery of agricultural fields are becoming more affordable and accessible. However, there is need to validate calibration of sensors on these systems when using them for quantitative analyses such as evapotranspiration, and other modeling for agricultural applications. The results of laboratory testing of a MicaSense (Seattle, WA, USA) RedEdge ${ }^{\text {TM }}$
\end{abstract}

Published in Precision Agriculture; online 20 December 2019.

DOI: 10.1007/s11119-019-09701-6

Copyright (C) 2019 Springer Science+Business Media, LLC. Used by permission. 
3 multispectral camera and MicaSense Downwelling Light Sensor (irradiance sensor) system using a calibrated integrating sphere were presented. Responses of the camera and irradiance sensor were linear over many light levels and became nonlinear at light levels below expected real-world, field conditions. Simple linear corrections should suffice for most light conditions encountered during the growing season. Using an irradiance sensor or similar system may not properly account for light variability in cloudy or partly cloudy conditions as also identified by others. A simple stand for aiding in reference panel imagining was also described, which may facilitate repetitive, consistent reference panel imaging.

Keywords: Unmanned aerial system, Remote sensing, Calibration, Reflectance

\section{Introduction}

Recent advances in unmanned aerial system (UAS) technology and U.S. federal regulations enabling more practical applications with small UASs have led to increased interest in using them for agricultural management (Woldt et al. 2014). Companies now widely market UASs for agricultural land surface imaging, as well as multispectral sensors or cameras for use in UAS-based applications for agricultural field management (Woldt et al. 2016a, b, c). While these UAS sensor/ platform systems are becoming more affordable and accessible, there is a need for independent verification of the scientific quality of the data produced from the combined flight, imaging, and image mosaicking process for the accurate retrieval of crop condition information. Some of these challenges have been identified by Zhang and Kovacs (2012), McKee (2017), and Laliberte et al. (2011). However, care must be taken during calibration as indicated by Wang and Myint (2015) regarding a common reference-target-based method.

The analysis of multispectral imagery from a UAS platform could be considered in one of two broad categories: qualitative and quantitative. The former may only require consistent or reasonably consistent conditions (e.g., lighting conditions) during an imaging mission. The primary qualitative use of imagery would be a visual interpretation of spatial and spectral image features. An example would be the visual inspection of an image to identify areas of poor crop development within a field to guide crop scouting efforts. The second class is quantitative, which may be used, for example, to model or quantify crop conditions (McKee 2017). This type of use requires imagery collected by calibrated instruments in a consistent manner to 
deliver products that are comparable in both space and time (Neale and Crowther 1994). An example from crop water management would be the use of multispectral imagery to compute evapotranspiration (ET) using reflectance-based crop coefficients (Neale et al. 1989). Reflectance-based, crop coefficient ET models (Bausch and Neale 1987; Neale et al. 1989) require a time series of multispectral imagery to compute crop coefficients. Energy balance ET models also rely on accurate estimations of crop biophysical parameters (e.g., leaf area index or crop height, Anderson et al. 2004; Li et al. 2005) based on multispectral reflectance imagery. In both cases, imagery that is rate for quantitative analysis, comparable in time, and economical to collect, is needed.

The objective of this study was to validate multispectral shortwave imagery collected using a commercially-available multispectral system and calibrated in terms of reflectance for the purposes of quantitative remote sensing. In particular, validation of the imagery for ET modeling was of interest. The primary purpose of this paper was to report the results of laboratory testing of a commercially-available multispectral sensor system using a calibrated integrating sphere. A secondary purpose was to discuss solutions to challenges encountered in efforts to collect irrigation management at the production scale $(\sim$ 50-130 ha).

\section{Materials and methods}

The sensor, or camera system included a MicaSense RedEdge ${ }^{\mathrm{TM}} 3$ multispectral camera (MicaSense, Seattle, WA, USA). The RedEdge was a five-band shortwave multispectral camera with separate non-interchangable, built-in lenses for each band. The RedEdge camera specifications were listed in Table 1. To aid in producing reflectance imagery, this camera also included a MicaSense Downwelling Light Sensor (DLS) to measure incoming irradiance in the five individual bands (MicaSense 2019a). However, detailed specifications of the DSL were not readily available. During field image collection, the camera system was mounted on a UAS, e.g., a DJI (Shenzhen, Guangdong, China) M-6oo UAS outfitted with a Gremsy (Ho Chi Minh City, Viet Nam) T1 gimbal, or FireFLY6 PRO (BirdsEyeView Aerobotics, Andover, NH, USA), operated 
Table 1 MicaSense RedEdge multispectral camera specifications (Micasense 2015)

\begin{tabular}{ll} 
Band name & FWHM band $(\mathrm{nm})$ \\
\hline Blue & $465-485$ \\
Green & $550-570$ \\
Red & $663-673$ \\
Red Edge & $712-722$ \\
Near IR & $820-860$ \\
Ground resolution & $82 \mathrm{~mm} /$ pixel (camera 120 m AGL) \\
Lens focal length (mm) & 5.5 \\
Lens field of view (degrees HFOV) & 47.2 \\
Imager size (mm) & $4.8 \times 3.6$ \\
Imagery resolution (pixels) & $1280 \times 960$
\end{tabular}

FWHM full width half max, AGL above ground level, HFOV horizontal field of view

by the Nebraska Unmanned Aircraft Innovation Research and Education (NU-AIRE) laboratory at the University of Nebraska-Lincoln.

The spectral response of the camera and the DLS were tested using a Labsphere (North Sutton, NH, USA) URS-600, Uniform Radiance Standard integrating sphere, a Labsphere SC-5500 Integrating Sphere System Control, and a power supply, likely a Labsphere LPS200-H Lamp Power Supply (Labsphere n.d.b); herein referred to collectively as a URS- 6oo, the integrating sphere, or the sphere. This system had a National Institute of Standard and Technology traceable calibration (Labsphere n.d.a, b) and was located at the Center for Advanced Land Management Information Technologies (CALMIT) at the University of Nebraska-Lincoln. The URS-6oo was an integrated system consisting of an $150 \mathrm{~mm}$ integrating sphere, a $150 \mathrm{~W}$ tungsten halogen lamp, a lamp power supply, an attenuator for controlling the amount of light from the lamp that was allowed to enter the sphere and a calibrated measurement system for determining energy levels inside the sphere (Labsphere n.d.a, b). The energy levels inside the sphere were finely variable from the attenuator being fully open to fully closed; though the nominal detector range did not go to zero (Labsphere n.d.b; L. Loudin, Labsphere, personal communication, 11 December 2019). The calibration of the sphere was National Institute of Standards and Technology traceable (Labsphere n.d.b) and was factory calibrated (Labsphere, 18 April 2011) in radiance values at multiple points, approximately every $50 \mathrm{~nm}$, with the attenuator at its 
maximum opening. The lamp power supply was intended to maintain a consistent current through the lamp filament with the lamp specification being 6.25 A (Labsphere n.d.b; L. Loudin, Labsphere, personal communication 11 December 2019). Though the power supply would have likely supplied a different current (L. Loudin, Labsphere, personal communication, 11 December 2019). The system output was intended to be similar to a black body emission of an object at a nominal 3200 K (Labsphere n.d.b; L. Loudin, Labsphere, personal communication, 11 December 2019); though the actual temperature was likely different (L. Loudin, Lab- sphere, personal communication, 11 December 2019). By keeping the temperature of the lamp constant and using the attenuator, energy levels inside the sphere could be changed without affecting the spectral quality of the radiation (L. Loudin, Labsphsere, personal communication, 11 December 2019). The measurement system was directly proportional to the amount of radiant flux present (Labsphere n.d.b). At the times of measurement, the lamp had little (i.e., less than $100 \mathrm{~h}$ ) use and the output of the integrating sphere, with the attenuator fully open, matched the output of the calibration. It was acknowledged that, as of this writing, the manufacturer recommended calibration of systems at $50 \mathrm{~h}$ and annual service of the power supply was considered good practice (L. Loudin, Labsphere, personal communication, 11 December 2019)-it is possible that this $50 \mathrm{~h}$ service recommendation included a bulb replacement. However, given the performance just mentioned, the system was assumed to be functioning adequately for the study.

Camera radiance measurements were made at the exit port of the sphere. Radiance levels as determined by the sphere's measurement system were directly transferred to the sensor. DLS Irradiance measurements were also made at the exit port. Radiance levels as determined by the measurement system were converted to irradiance units and then com- pared to the irradiance sensor. The URS-6oo had an attenuator for adjusting light levels and a sensor system for monitoring the light level inside the sphere. Light levels in the sphere were recorded in electrical current (amp) output of the light level sensor. In the results section, these light levels have been converted to radiance ( $\mathrm{W} \mathrm{sr}{ }^{-1} \mathrm{~m}^{-2} \mathrm{~nm}^{-1}$ ) and irradiance $\left(\mathrm{W} \mathrm{m}^{-2} \mathrm{~nm}^{-1}\right.$ ) for the full-width at half max (FWHM) for the camera bands reported in MicaSense (2015) and Table 1 using the factory calibration (Labsphere, 18 April 2011). The DLS bands were assumed to be identical to the camera bands. 
The system was tested on two separate occasions. Measurements were taken over a wide range of light levels to check the linearity of both the camera and DLS. Starting at a light level above normal reflected field conditions for vegetation, light levels were repeatedly cut in half for a total of 12 or 13 light levels (depending on the test). During the first testing period, output from the URS-600 sensor system ranged from a high of $1024 \times 10^{-9}$ A to a low of $0.25 \times 10^{-9}$ A for both the camera and the DLS for a total of 13 light levels. The change in light intensity was greater than three orders of magnitude. During these first test runs, there was some uncertainty as to the response time of the camera from the time of triggering the camera image capture with a wireless tablet and the actual image capture. The integrating sphere light level was changed soon after triggering image capture. If the delay between triggering on the camera and image capture was too great, the image could have captured the changing light level between integrating sphere settings. There- fore, a second test was executed with the camera triggered with a laptop and assuring that the response time was honored. Light levels were similar in the second test ranging from $1024 \times 10^{-9}$ A to a low of $0.5 \times 10^{-9}$ A (12 light levels) for the camera and $2048 \times 10^{-9} \mathrm{~A}$ to a low of $1.0 \times 10^{-9} \mathrm{~A}$ for the DLS (12 light levels). The reason for the shift in the light levels for the DLS was that in natural conditions, the irradiance was greater than the light reflected off the ground surface. During the second test, it was discovered that the red and NIR lenses had smudges on them during the testing. The lenses were cleaned and additional images were collected for these two bands at $256 \times 10^{-9}, 32 \times 10^{-9}$, and $4 \times 10^{-9} \mathrm{~A}$ for comparison. The NIR from these additional images and the origin a from this date were used to produce a set of corrected NIR data from this date.

The camera images were converted to ASCII format using ArcGIS 10.4 (ESRI, Red- lands, CA, USA) and radiometrically corrected following MicaSense (2017b) using Micro-soft Excel. Radiometric correction parameters were retrieved from the image metadata using ExifTool (P.Harvey, https://www.sno.phy.queensu.ca/ phil/ exiftool/). A mask was created for each set of images to clip out portions of the image that appeared to contain non-reference source features. (These included material used to mask the lenses that were not in full view of the sphere-one camera lense had full view at a 
time-and circular artifacts caused by either the sphere's view port or the camera body.) Unresponsive pixels were identified by collecting dark images. These pixels were identified as those that produced the peak raw data value in dark imagery. Such pixels were masked out using band-specific mask images. Dark images were collected in a darkened room with the camera inside a carrying case. Thus, pixels producing high output values under these conditions would be unresponsive pixels. (Dark imagery was only collected near the time of the first round of testing and was assumed to be similar for the second also.) The mean of remaining pixels was computed for comparison with the integrating sphere and DLS data. Linear regression was used for formal comparisons.

The system behavior was further investigated by taking images outdoors under natural lighting conditions on December 20, 2017. For such, the camera was mounted looking from nadir, over two MicaSense Calibrated Reflectance Panels in a grassed area on the University of Nebraska-Lincoln campus in Lincoln, NE $\left(40.83^{\circ} \mathrm{N}, 96.67^{\circ}\right.$ W, Google Earth Pro, accessed May 24, 2018). The purpose of the reference panel imagery was to test the ability of the DLS to produce reflectance imagery under natural lighting conditions. This was also a test that could more easily be performed by practitioners. While December was a very low solar angle time of year to be capturing reference panel images at this latitude, it was a clear or mostly clear sky day. The images were corrected and masked as done for the integrating sphere study. Furthermore, only the inner $\sim 64 \%$ of the panels in each image were included in the analysis. The panel images were taken at different distances (e.g., 0.4 to $\sim 1.2 \mathrm{~m}$ ) above the panels and with different panel orientation (portrait/landscape).

\section{Results and discussion}

\section{Laboratory calibration results}

The camera response was compared to the integrating sphere light levels (Fig. 1). The responses were quite linear, except at low light levels $\left(R^{2} \geq 0.9997\right.$ in the linear scale). The comparison of images from before and after cleaning the red and NIR lenses on the second testing 

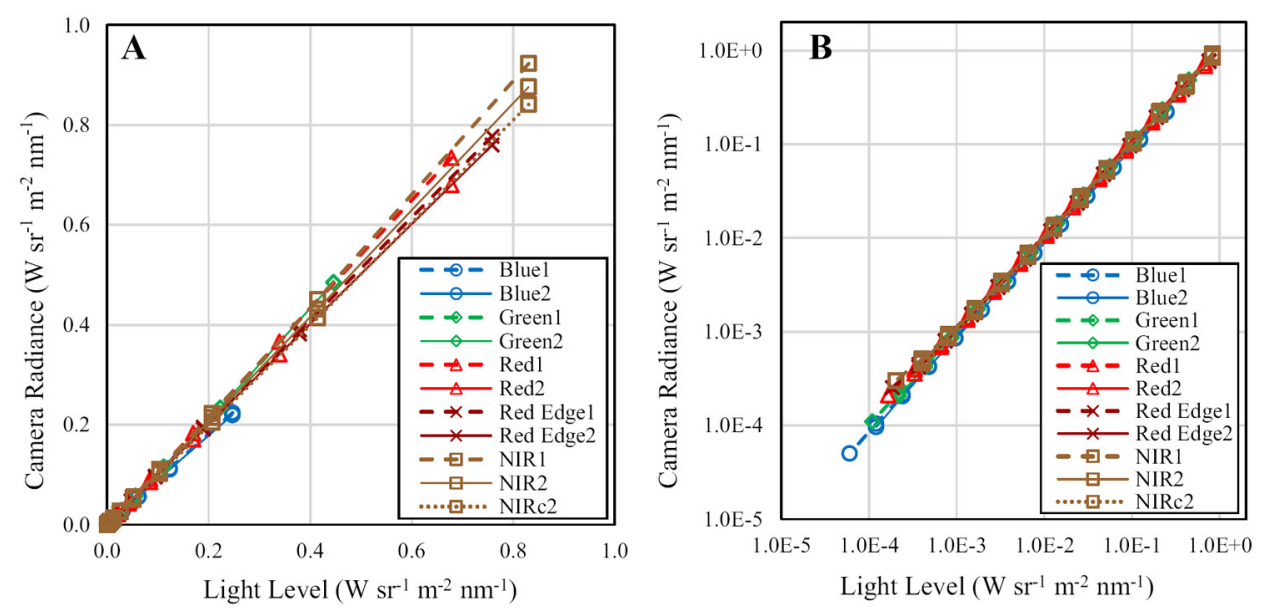

Fig. 1 Here, NIR is near infrared; 1 and 2 represent the two different tests; NIRc2 was corrected based on a second set of measurements. The plots were simply in two different scales: linear (a) and $\log (\mathbf{b})$. Light level is for the integrating sphere over the FWHM of the e 2015) using the sphere's factory calibration (Labsphere, 18 April 2011)

occasion indicated $<1 \%$ difference in radiance for the red and $\sim 4 \%$ difference for the NIR, with the pre-cleaning images being greater than the post-cleaning images. The average ratio of the cleaned-lens NIR radiance to the uncleaned-lens radiance was used to adjust the whole uncleaned NIR dataset (NIR2c in Fig. 1). The unexpected decrease in response after lens cleaning was noted and the cause was unknown, however the difference was relatively small $(<1 \%$ for red and $\sim 4 \%$ for NIR). Camera radiances from all bands appeared proportional to one another over most light levels and would likely perform well when subjected to varying reflectance in a field setting. It was observed that radiometrically-corrected imagery had some radial pattern of variation in pixel values (Fig. 2a, b), suggesting an overcorrection in the vignetting correction. However, under many light conditions, the coefficient of variation of the pixel radiances was $<7 \%$, but was much greater in some cases at lower levels (Fig. 2c). No attempt was made to further correct the ugh it was acknowledged that such may be warranted.

The response of the DLS appeared to be somewhat similar to the camera, though it appeared less accurate at low light levels as indicated 

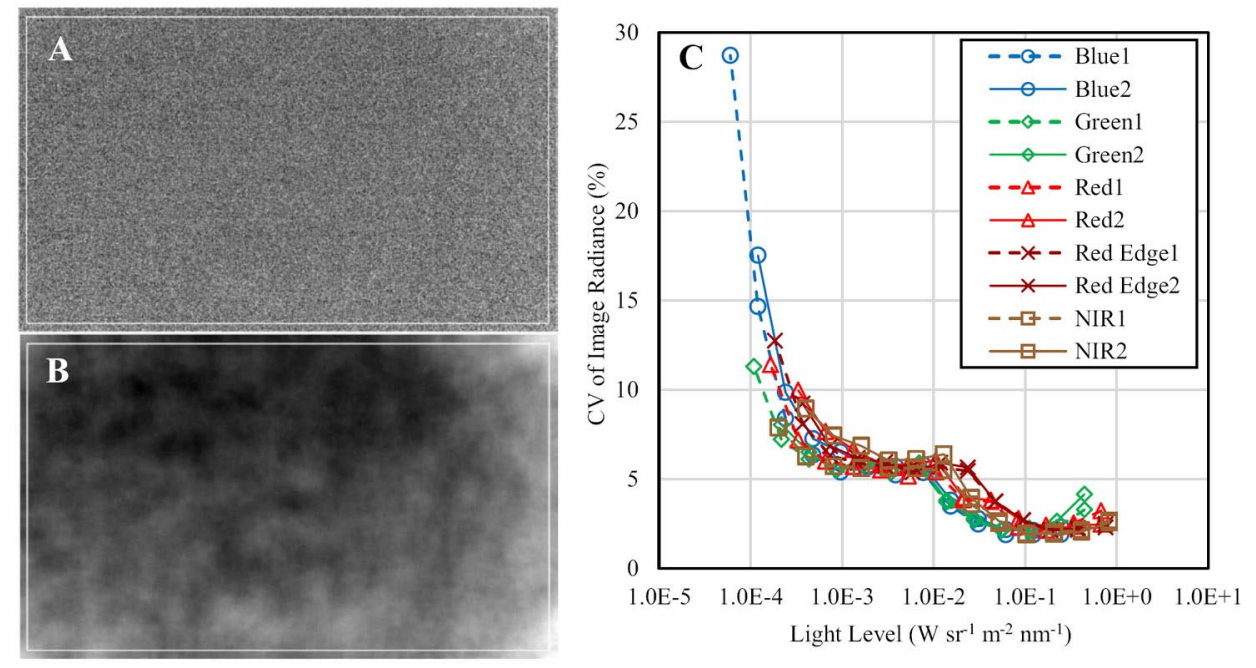

Fig. 2 Image showing the corrected radiance values for near infrared in the first test at about a $1.3 \times 10^{-2} \mathrm{~W} \mathrm{sr}^{-1} \mathrm{~m}^{-2} \mathrm{~nm}^{-1}$ light level (a), the running mean radiance using a 20 pixel radius for the same image (b), and a plot of the coefficient of variation (CV) within the masked portion of each integrating sphere image (c). The white rectangles in (a) and (b) indicate the approximate limit of edge effects in (b). Here, NIR is near infrared; 1 and 2 represent the two different tests. Light level is for the integrating sphere over the FWHM of the res $g$ the sphere's factory calibration (Labsphere, 18 April 2011)

by non-linear features in the low light range (Fig. 3). The $R^{2}$ was 1.0000 in the linear scale for all except the NIR in the second test, which was $R^{2}=0.9931$, notable because of the log nature of the data. The relatively low response of the DLS at the highest light level for the NIR in the second integrating sphere test may have been an indication of lighting conditions above the sensor sensitivity. However, because of the sampling interval, the threshold light level at which the nonlinearity began was not identified. Furthermore, this high light level was greater than a range of observed values from imagery collected in the field during the summer of 2018 (Figs. 3, 4, 5). Based upon a factory calibration (Labsphere, 18 April 2011), the integrating sphere lamp emission was greatest for the NIR and decreased for each of the subsequently shorter wavelength bands using the manufacture's specified band widths (MicaSense 2015). From Figs. 1 and 3, a relatively linear relationship was observed between the two sensors. 

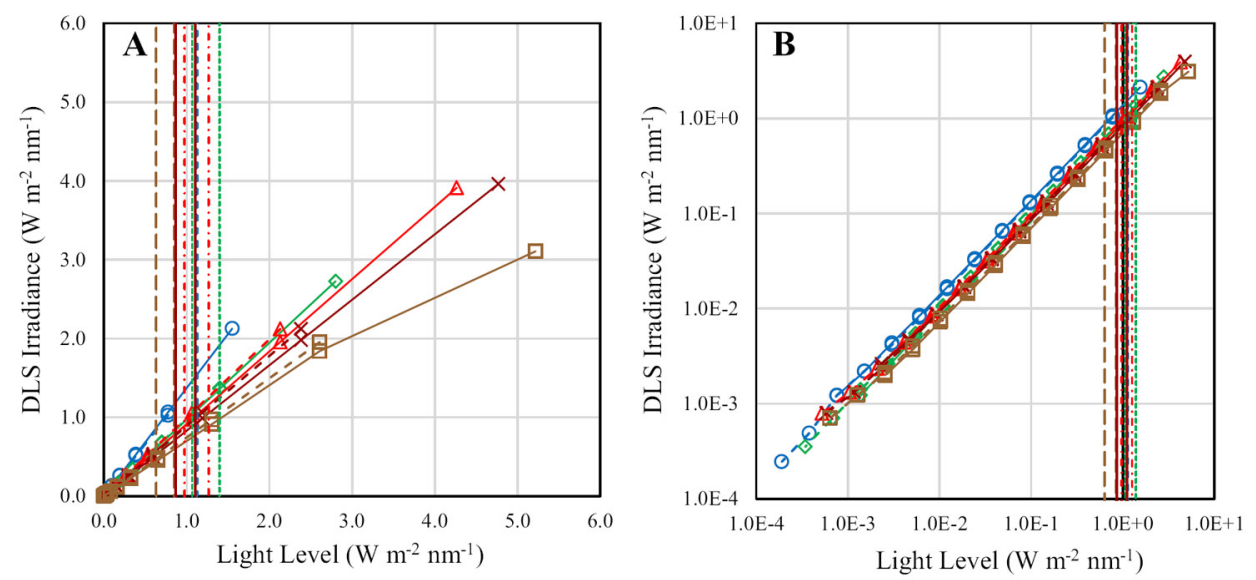

\begin{tabular}{|c|c|c|c|c|}
\hline $\begin{array}{l}--\sigma-\cdot \text { Bluel } \\
-\triangle-\text { Red2 } \\
---\cdot \text { Blue Range }\end{array}$ & $\begin{array}{l}- \text { Blue2 } \\
--\star-\cdot \text { Red Edgel } \\
--\cdot \text { Green Range }\end{array}$ & $\begin{array}{l}--\infty-\text { Greenl } \\
\longrightarrow \leftarrow \text { Red Edge2 } \\
-\cdots-\text { Red Range }\end{array}$ & $\begin{array}{l}- \text { Green2 } \\
--\square-\cdot \text { NIR1 } \\
\text { - Red Edge Range }\end{array}$ & $\begin{array}{l}--\Delta-\cdot \text { Redl } \\
-\square-\text { NIR2 } \\
--- \text { NIR Range }\end{array}$ \\
\hline
\end{tabular}

Fig. 3 MicaSense Downwelling Light Sensor (DLS) response at different integrating sphere light levels. Here, NIR is near infrared; 1 and 2 represent the two different tests. The plots were simply using two-different scales: linear (a) and log (b). The vertical "Range" lines represent an approximate range of observed irradiance values from late morning image captures on 30 May, 27 June, 24 July, 29 August, and 26 September 2018 in Eastern Nebraska Nebraska (lat. 41.2 ${ }^{\circ} \mathrm{N}$, lon. 96. $5^{\circ} \mathrm{W}$, Google Earth Pro, accessed 8 October 2018). Light level is for the integrating sphere over the FWHM of the respective camera band (MicaSense 2015) using the factory calibration (Labsphere, 18 April 2011)

To assess the ability of the system to provide accurate reflectance data, the camera response was plotted at different light levels versus the DLS response (Fig. 4). Here, the DLS measurements were converted into radiance ( $\mathrm{W} \mathrm{sr}^{-1} \mathrm{~m}^{-2} \mathrm{~nm}^{-1}$ ) for comparison. The $R^{2}$ was greater than or equal to 0.9996 in the linear scale for all bands and tests. The plots for each band and test produced were linear (Fig. 4) except at low light levels for the green and blue bands. Again, the integrating sphere lamp emission increases with increasing wavelength for the camera bands (Labsphere calibration 18 April 2011; MicaSense 2015). Therefore, the blue and green bands may have detected light levels below their sensitivity at the lower range, while this may not have occurred in the other bands (Fig. 4). The approximate observation ranges for all bands were above the low levels that appeared erroneous in the blue and green. In fact, the approximate observation range for blue was greater than the light levels used in the first test (Blue1; Fig. 3). While the plots in Fig. 4 were linear, the apparent slopes were not near unity. (The offsets of the lines from unity in 

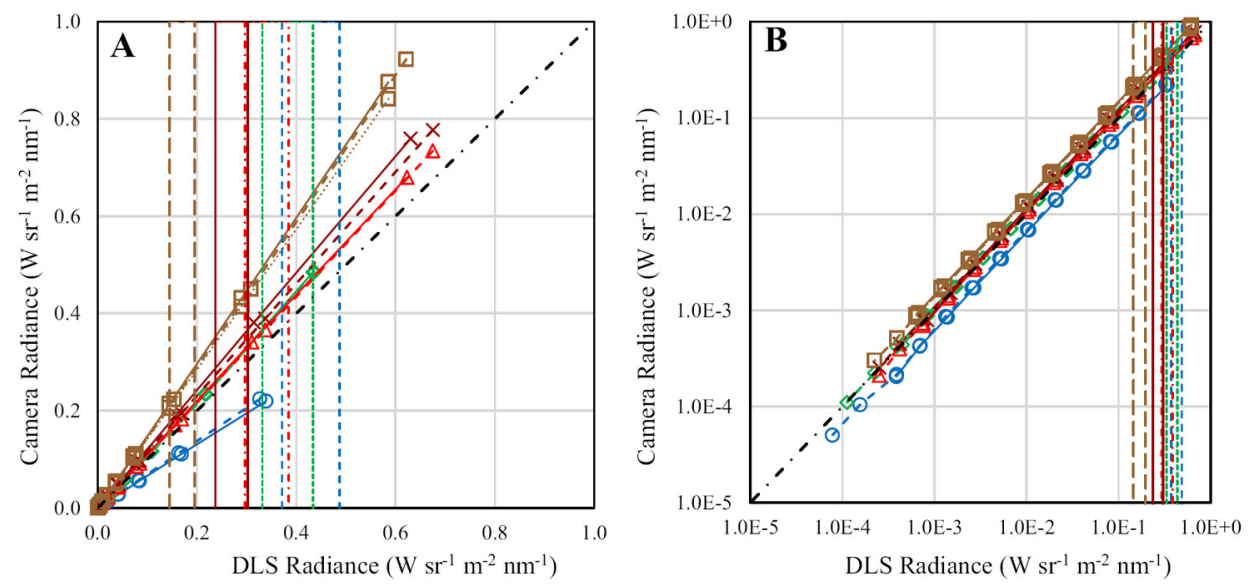

\begin{tabular}{|c|c|c|c|c|}
\hline 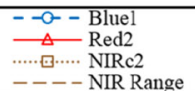 & $\begin{array}{l}0-\text { Blue2 } \\
--x-\text { Red Edgel } \\
--- \text { Blue Range } \\
-\cdot-1: 1\end{array}$ & $\begin{array}{l}--\diamond-\text { Green1 } \\
\longrightarrow x \text { Red Edge2 } \\
x \quad \text { Green Range }\end{array}$ & 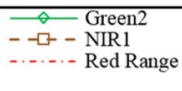 & $\begin{array}{l}--\Delta-\text { Redl } \\
\square \quad \text { NIR2 } \\
\square \text { Red Edge Range }\end{array}$ \\
\hline
\end{tabular}

Fig. 4 Camera radiance versus MicaSense Downwelling Light Sensor (DLS) radiance at different integrating sphere light levels. Here, NIR is near infrared; 1 and 2 represent the two different tests; NIRc2 was corrected based on a second set of measurements. The plots were simply using two-different scales: linear a) and log (b). The vertical "Range" lines represent an approximate range of observed irradiance values late morning image captures on 30 May, 27 June, 24 July, 29 August, and 26 Septe Eastern Nebraska (lat. $\sim 41.2^{\circ} \mathrm{N}$, lon. $\sim 96.5^{\circ} \mathrm{W}$, Google Earth Pro, accessed 8 October 2018)

the logarithmic scale was similar to results in the linear scale having slopes not equal to unity.) For example, Bluez had a slope of about 0.65 and NIR2 had a slope of about 1.50.

Crop and soil surfaces will not have reflectance values near unity (as was the ideal depicted in Fig. 4). Therefore, to further examine the effect that these uncorrected responses would have on computed reflectance, the camera radiance was divided by the DLS response to get a simulated reflectance. To make this comparison representative, the data were shifted such that the camera radiance from one light level below the irradiance data was used, thus simulating a 50\% apparent reflectance condition (Fig. 5). The camera radiances were similarly shifted two light levels with respect to the irradiance data to simulate a $25 \%$ apparent reflectance condition (Fig. 5). It was notable that the DLS and camera responses were not uniformly proportional, across light levels, with the largest discrepancies having at the $\sim 5.2 \mathrm{~W} \mathrm{~m}^{-2} \mathrm{~nm}^{-1}$ of the camera and DLS appeared to change with light level. 

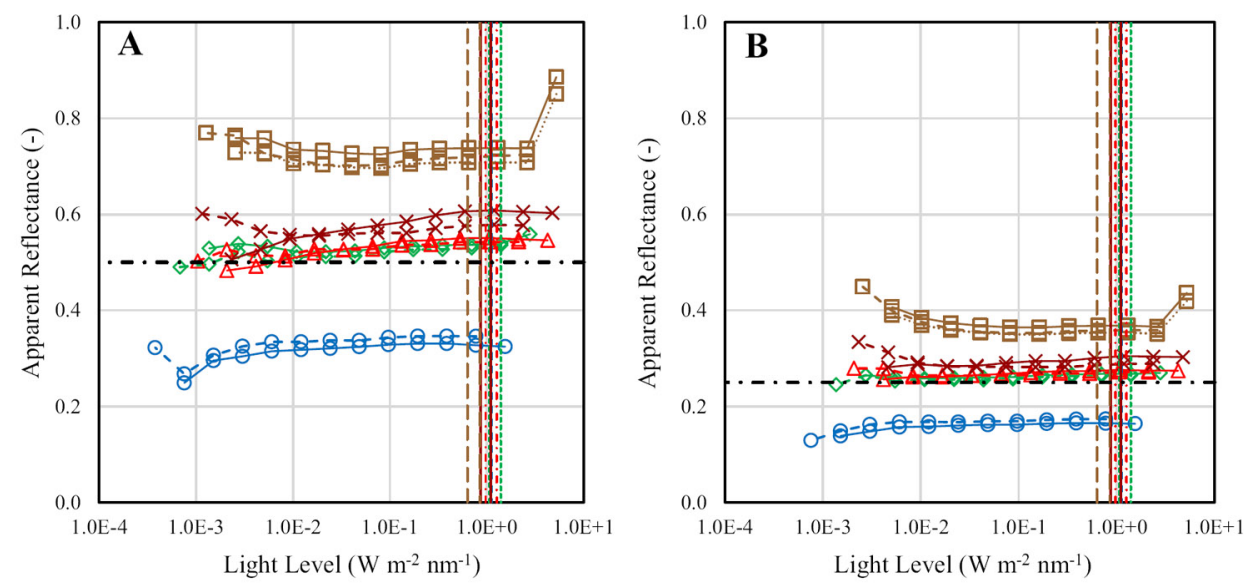

\begin{tabular}{|c|c|c|c|c|}
\hline $\begin{array}{l}--a-- \text { Bluel } \\
-\triangle-\text { Red2 } \\
\ldots \ldots . \cdots \cdot \text { NIRc2 } \\
---- \text { NIR Range }\end{array}$ & $\begin{array}{l}\text { O- Blue2 } \\
--x-- \text { Red Edgel } \\
---- \text { Blue Range } \\
-\cdot-\cdot 0.25\end{array}$ & $\begin{array}{l}-\leadsto-\text { Greenl } \\
\longrightarrow \quad \text { Red Edge2 } \\
-\cdots-- \text { Green Range }\end{array}$ & $\begin{array}{l}\diamond-\text { Green2 } \\
--\square-\text { NIR1 } \\
\cdots-- \text { Red Range }\end{array}$ & $\begin{array}{l}--\Delta-\text { Redl } \\
\square-\text { NIR2 } \\
\square \text { Red Edge Range }\end{array}$ \\
\hline
\end{tabular}

Fig. 5 Camera radiance divided by MicaSense Downwelling Light Sensor (DLS) radiance from two-times the light level (a) and from four-times the light level (b) at different integrating sphere light levels (presented for the DLS). The ratio of radiance/irradiance is called "apparent reflectance" here. Also, NIR is near infrared; 1 and 2 represent the two different tests; NIRc2 was corrected based on a second set of measurements. The vertical "Range" lines represent an approximate range of observed irradiance values from late morning image captures on 30 May, 27 June, 24 July, 29 August, and 26 September 2018 in Eastern Nebraska (lat. 41.2 ${ }^{\circ}$ N, lon. $96.5^{\circ} \mathrm{W}$, Google Earth Pro, accessed 8 October 2018). Light level is for the integrating sphere over the FWHM of the respective camera band (MicaSense 2015) using the factory calibration (Labsphere, 18 April 2011).

The response of the camera and DLS appeared to change with light level. The most anomalous responses in Fig. 5 were below these light levels; with the exception of NIR, which was well above the observed light level range. The response of NIR and blue in Fig. 5 was unexpected based upon the expected apparent relflectance. However, considering the response of the DLS in Fig. 3 as compared to the camera in Fig. 4, the results in Fig. 5 followed logically. In this, the response of the DLS seemed suspect as the temperature of the integrating sphere lamp emission was less in the blue than in the NIR as previously cited. Thus, the camera response (Fig. 4) was more expected. This was further investigated by collecting images over reflectance panels (Fig. 6 ). It was apparent that the DLS and camera combination did not accurately replicate the panel reflectance as indicated using relative reflectance (DLS-based reflectance divided by the nominal reference panel 

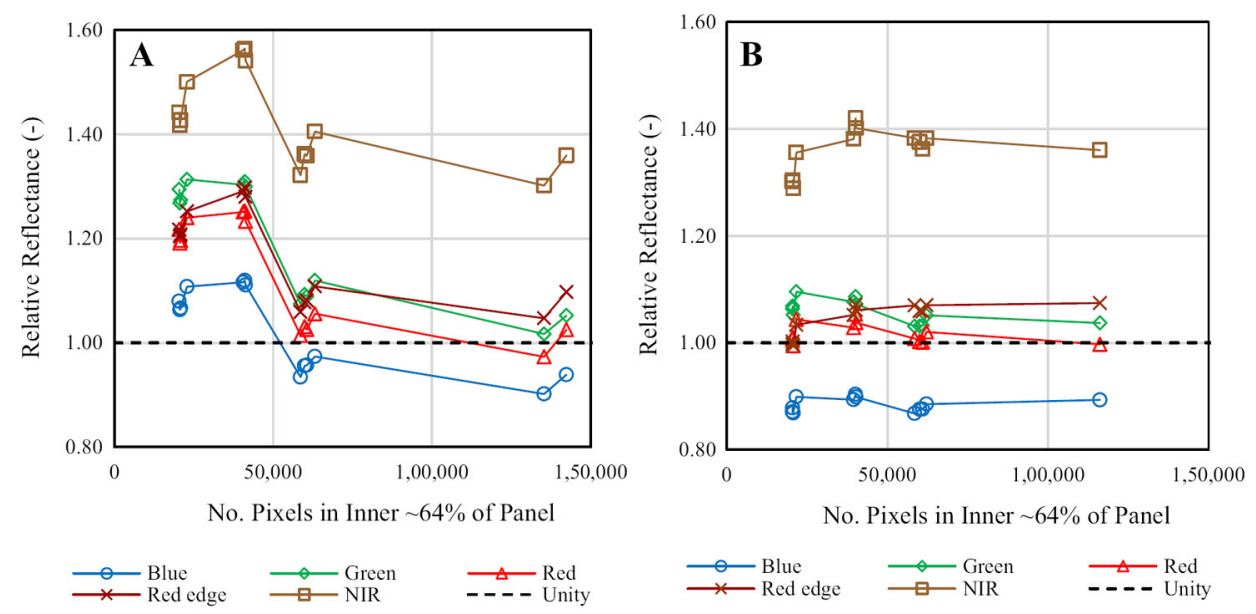

Fig. 6 Camera and MicaSense Downwelling Light Sensor (DLS)-based reflectance over reference panels divided by reference reflectance (relative reflectance) for two reflectance panels (a, b). Images were collected on December 20, 2017 in Lincoln, Nebraska. Individual lines are for individual bands, NIR is near infrared. Pixel counts decrease with increasing distance between the camera and panels.

reflectance provided through personal communication from the manufacturer, e.g., ca. 2017). This was particularly observable for the NIR and blue as was to be expected from Fig. 5. There was some odd behavior for one of the panels (Fig. 6A) in the images with low pixel counts, possibly caused by the low pixel count. However, the blue and NIR did have the same relative behavior under natural light and compared to the panels as they did using the integrating sphere data (Fig. 5).

From the results, it was apparent that data collected using only the camera and DLS combination will require further adjustment to be used to produce reflectance values. It appeared that simple linear corrections to the irradiance data should be sufficient. The largest adjustments would be for the blue and NIR bands. The use of reflectance panels is necessary and is a conventional remote sensing method (Jackson et al. 1987; Neale and Crowther 1994) and was suggested by the manufacturer (MicaSense 2019a, b; McKee 2017).

\section{Field considerations}

Some additional challenges encountered when imaging agricultural fields are detailed here. These challenges include: changing 


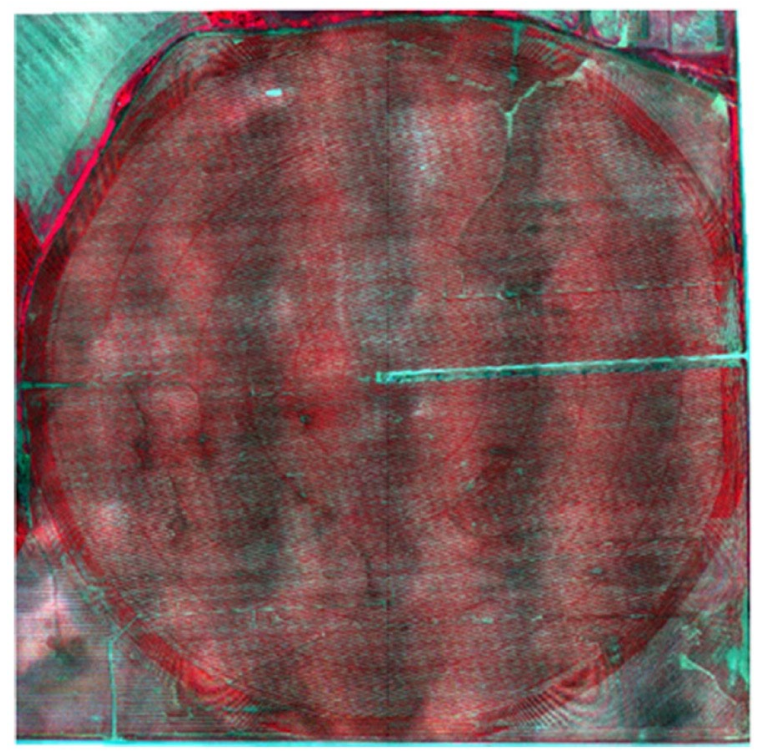

Fig. 7 False color infrared mosaic depicting striping effect. The image was collected over a field in Eastern Nebraska and was generated from UAS acquired multispectral imagery processed using Pix4D and DLS data (figure from Maguire 2018).

environmental conditions during image collection (cloud or sun movement, winds, etc., e.g., Maguire 2018) as a typical UAS flight duration lasts about 20-25 min for a 50 ha field. Striping effects have been observed in some image mosaics over areas of $50+$ ha when using the camera/DLS system (Fig. 7, Maguire 2018). It was suspected that one possible cause was error in the DLS measurements due to the attitude orientation of the UAS (e.g., caused by flight behavior, wind direction, etc.) when using a fixed wing system with respect to the sun (Maguire 2018). It may be possible to correct for this based on geometry, e.g., using the equations of Allen et al. (2006), see also Pix4D 4.3.27 (Pix4D S.A., Lausanne, Switzerland). Additional variability can be intro- duced due to bidirectional reflectance effects when the surface is not viewed from nadir (Zhang and Kovacs, 2012; Lelong et al. 2008). Flying with a multi-rotor system and gim- ble such as the one described in the Materials and Methods section may also reduce these effects.

Variable lighting conditions during a flight of sufficient duration to cover a production row crop field may also be a challenge (Maguire 2018). Mottled effects have been observed in mosaics based on intermittent cloud cover and shadows on the ground surface as described in the companion work of Maguire (2018). Although an aircraft-mounted irradiance sensor may help to correct for varying lighting during a flight (see also MicaSense 2019a), it cannot be used to 


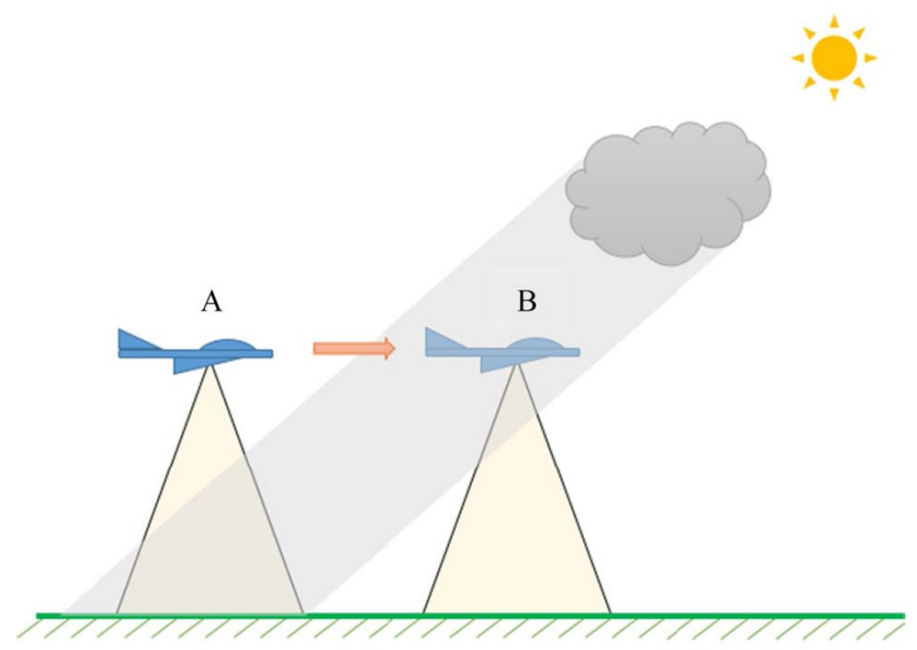

Fig. 8 Depiction of variable lighting between an irradiance sensor mounted on the aircraft and the land surface under the aircraft

adequately capture the effects of patchy cloud cover as demonstrated in Fig. 8 and as cautioned by MicaSense (2017a) and mentioned by Maguire (2018). In position A of Fig. $\underline{8}$, the aircraft is in nearly full sun, but the ground is shaded from a cloud. The opposite is the case in position B. This can be illustrated by ignoring differences in direct and diffuse light, and assuming that true surface reflectance is $40 \%$ under both conditions and assuming the light in the shadow was $50 \%$ of that outside of the shadow. At position A, the apparent reflectance would be $20 \%$ or half of reality. At posi- tion B, the apparent reflectance would be 80\%. MicaSense (2017a) and Maguire (2018) describe this variable lighting of sensor and target challenge. The same challenge might exist for ground-based irradiance sensors; the camera view and irradiance sensor may not be similarly illuminated. It is therefore recommended that even when using real-time irra- diance data, that imagery be collected under clear-sky conditions and that reflectance panel images be collected before and after image acquistion flights; e.g., MicaSense (2019b) mention such acquisition (see also Mckee 2017).

Finally, the process of reflectance panel image capture can be improved by using a stand or holding device for the aircraft or camera. For the former, the aircraft with camera mounted is placed on the stand over the reflectance panel. This allows for more consist- ency in collecting panel shots, leveling of the aircraft (and camera), and for the 


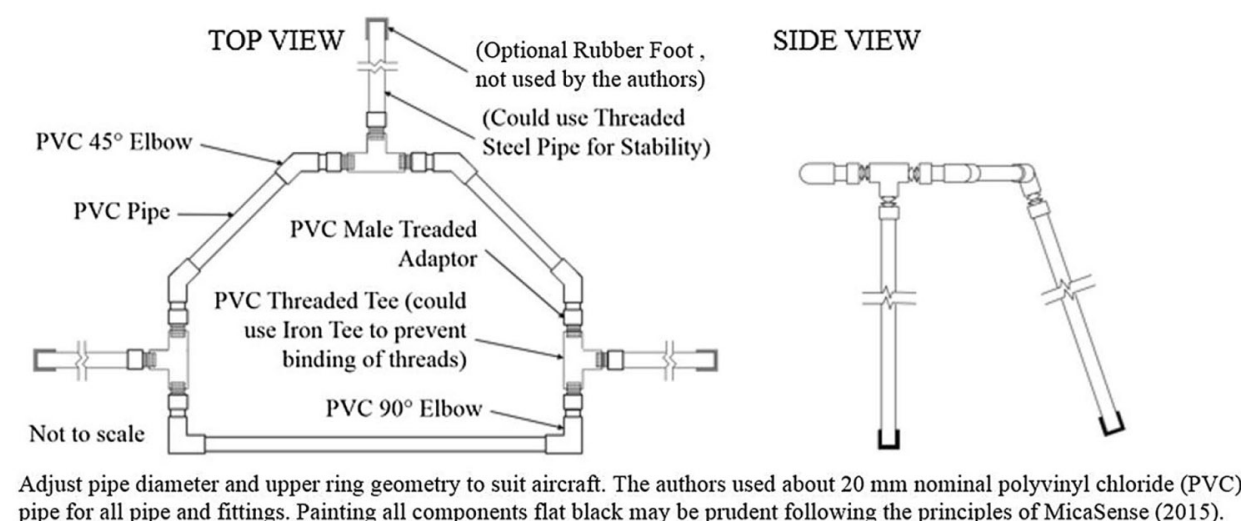

Fig. 9 Schematic of a tripod for holding a UAS during reflectance panel image capture
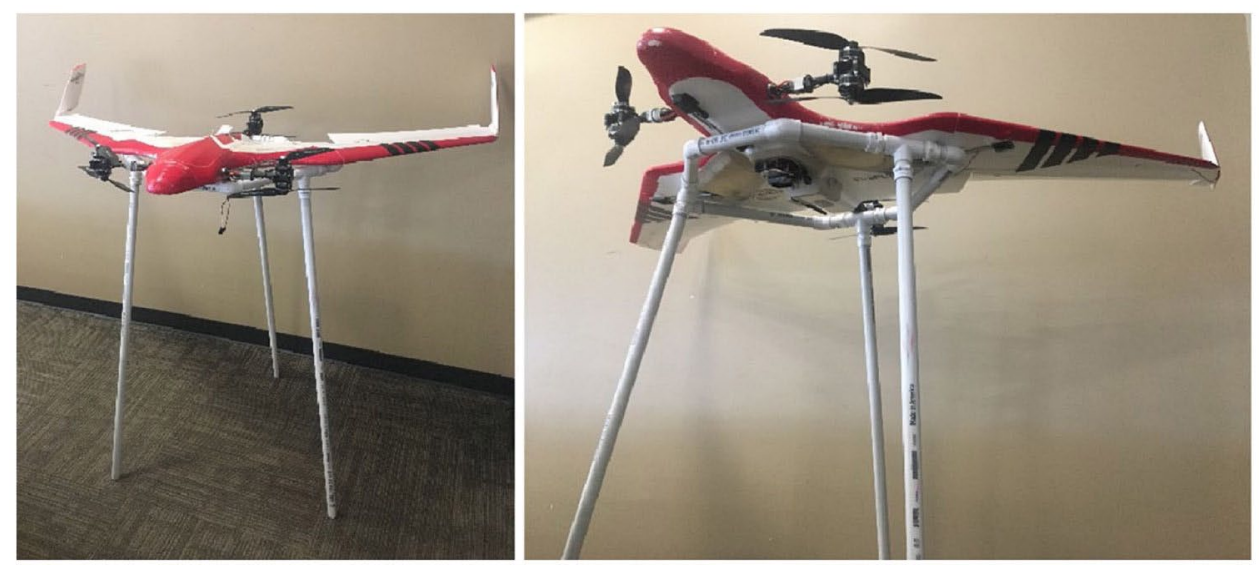

Fig. 10 Top and bottom view photos of a FireFLY6 PRO fixed wing UAS atop the holding tripod

operator(s) to remain away from the panel (see MicaSense 2015). A simple tripod was constructed of PVC pipe similar to Figs. 9 and 10 for this purpose. The tripod was made of easily obtained materials and could thus be constructed by other investigators.

When considering the dimensions of the tripod, one should consider the minimum solar zenith angle at the study site; this was computed to be about 18 degrees on the summer solstice at the location of this study using equations from Allen et al. (2006) and Jensen and Allen (2016). Thus, the height of the stand would need to be more than 3.1 times the distance of the camera to the southern edge of the aircraft, which was expected to be about $0.3 \mathrm{~m}$. Therefore, the stand should be $>1 \mathrm{~m}$ tall in the conditions of this study. 
While PVC components were used here, using threaded iron tees for the leg hinges would allow for adjustment of the tripod without binding that happens when plastic tees were used. Steel or aluminum pipe for the legs may also improve stability. The geometry of the top ring could be modified based on the UAS used. If an adjustment or repair is needed, the top ring could be cut and recoupled after the adjustment. While this tripod was not painted, flat black paint may be a prudent in the Spirit of MicaSense (2015). Collectively, in the dynamic field environment it is difficult to acquire science-grade spectral imagery as compared to indoor lab conditions and several ideas highlighted here need to be considered to effective systems for the retrieval of many crop characteristics.

\section{Conclusions}

Quantitative shortwave multispectral remote sensing products may be produced using commercially available sensors, or cameras, and unmanned aircraft platforms. However, care should be taken to validate the data. Under most lighting conditions tested here, the DLS and the camera responses were proportional and linear, suggesting that simple corrections could be applied to produce reflectance products from the combined camera and DLS system. Multispectral cameras and combined camera/irradiance sensor system should be validated by the user prior to using them to produce reflectance imagery. The reference panel method should be sufficient for most uses. Results indicated that incoming irradiance sensors may not be adequate to correct for varying light in cloudy conditions and can be affected by the attitude of the UAS during flight (e.g., resulting from wind direction) as also observed by others. Reflectance panel images are still an important part of sur- face reflectance imaging. Panel images can be improved using a simple stand as described here. As others have also demonstrated, when collecting imagery for quantitative analysis, proper image processing is required. The following practices are recommended: imagery be collected in clear sky conditions, reference reflectance panels be used, a stand be used when collecting panel imagery, and irradiance-sensor-based reflectance be verified using reference panel images. It is agreed herein with other literature that many, if not all of these steps are already commonly accepted remote se at they should not be ignored and should be understood by end users. 
Acknowledgments - Support for the project was provided by: the United States Department of Agriculture-National Institute of Food and Agriculture for an Agriculture Food and Research Initiative grant (Award No. 2017-67021-26249); the Robert B. Daugherty Water for Food Global Institute at the University of Nebraska; the University of Nebraska-Lincoln Institute of Agriculture and Natural Resources Agricultural Research Division; and the Nebraska Agricultural Experiment Station through funding from the Hatch Act (Accession Number 1009760). We thank Dr. John Gamon, UNL, for his advice. The authors declare that they have no conflict of interest. The datasets generated and current study are available from the corresponding author upon reasonable request.

Data availability The datasets generated and/or analyzed during the current study are available from the corresponding author upon reasonable request.

Conflict of interest - The authors declare they have no conflict of interest.

\section{References}

Allen, R. G., Trezza, R., \& Tasumi, M. (2006). Analytical integrated functions for daily solar radiation on slopes. Agricultural and Forest Meteorology, 139(1-2), 55-73. https://doi.org/10.1016/j.agrfo rmet.2006.05.012.

Anderson, M. C., Neale, C. M. U., Li, F., Norman, J. M., Kustas, W. P., Jayanthi, H., et al. (2004). Upscaling ground observations of vegetation water content, canopy height, and leaf area index during SMEXo2 using aircraft and Landsat imagery. Remote Sensing of Environment, 92(4), 447-464. https:// doi. org/10.1016/j.rse.2004.03.019.

Bausch, W. C., \& Neale, C. M. U. (1987). Crop coefficients derived from reflected canopy radiation: A con- cept. Transactions of the ASAE, 30(3), 703709. https://doi.org/10.13031/2013.30463.

Jackson, R. D., Moran, M. S., Slater, P. N., \& Biggar, S. F. (1987). Field calibration of reflectance panels. Remote Sensing of Environment, 22(1), 145-158.

Jensen, M. E., \& Allen, R. G. (Eds.). (2016). Evaporation, evapotranspiration, and irrigation water require- ments. ASCE Manuals and Reports on Engineering Practice No. 70. Task Committee on Revision of Manual 70 (p. 744). Reston, VA, USA: Environmental and Natural Resources Institute, American Society of Civil Engineers.

Labsphere. (n.d.a). SC-550o integrating sphere system control. SX-01635-0oo, Rev. 4. North Sutton, NH, USA: Labsphere, Inc.

Labsphere. (n.d.b). URS-60o uniform radiance standard. AQ-00459-0oo, Rev. 1. North Sutton, NH, USA: Labsphere, Inc.

Laliberte, A., Goforth, M. A., Steele, C. M., \& Rango, A. (2011). Multispectral remote sensing from unmanned aircraft: Image processing workflows and applications for rangeland environments. Remote Sensing, 3(11), 25292551. https://doi.org/10.3390/rs3112529. 
Lelong, C. C. D., Burger, P., Jubelin, G., Roux, B., Labbé, S., \& Baret, F. (2008). Assessment of unmanned aerial vehicles imagery for quantitative monitoring of wheat crop in small plots. Sensors, 8(5), 3557- 3585. https://doi. org/10.3390/s8053557.

Li, F., Kustas, W. P., Prueger, J. H., Neale, C. M. U., \& Jackson, T. J. (2005). Utility of remote sensing- based two-source energy balance model under low- and highvegetation cover conditions. Journal of Hydrometeorology, 6, 878-891. https:// doi.org/10.1175/JHM464.1.

Maguire, M. (2018). An evaluation of unmanned aerial system multispectral and thermal infrared data as information for agricultural crop and irrigation management. M.S. Thesis, Biological Systems Engi- neering Department, University of Nebraska-Lincoln, Lincoln, NE, USA. Retrieved November 29, 2019 from http://digitalcommons.unl.edu/biosysengdiss/82/.

McKee, M. (2017). The remote sensing data from your UAV probably isn't scientific, but it should be! Pro-ceedings of SPIE 10218, Autonomous Air and Ground Sensing Systems for Agricultural Optimization and Phenotyping II, 102180 M. SPIE Commercial + Scientific Sensing and Imaging 2017, Bellingham, WA, USA: SPIE. https://doi.org/10.1117/12.2267722.

MicaSense. (2015). MicaSense RedEdge ${ }^{\mathrm{TM}} 3$ multispectral camera user manual (p. 33). Rev 06, October 2015. MicaSense, Seattle, WA. Retrieved November 28, 2019 from https://support.micasense.com/hc/ en-us/ articles/215261448-RedEdge-User-Manual-PDF-Download.

MicaSense. (2017a). Light sensors: The basics (DLS and sunshine sensor). Dated 30 August 2017. Retrieved November 28, 2019, from https://support.micasense.com/hc/en-us/ articles/1150027820 o8-Light-Sensors-the-Basics-DLS-and-Sunshine-Sensor.

MicaSense. (2017b). RedEdge camera radiometric calibration model. Last Updated 19 August 2019. Retrieved January 10, 2018 from https://support.micasense.com/hc/en-us/ articles/1150003511 94-RedEdge-Camera-Radiometric-Calibration-Model.

MicaSense. (2019a). What does RedEdge's downwelling light sensor do for my data?. Updated 19 August 2019. Retrieved November 28, 2019 from https:// support.micasense.com/hc/en-us/articles/21990 1327-What-does-RedEdge-sDownwelling-Light-Sensor-do-for-my-data.

MicaSense. (2019b). Use of calibrated reflectance panels for RedEdge data. Last Updated 24 July 2017. Retrieved November 28, 2019 from https:// support.micasense.com/hc/en-us/articles/1150007655 14-Use-of-CalibratedReflectance-Panels-For-RedEdge-Data.

Neale, C. M. U., Bausch, W. C., \& Heermann, D. F. (1989). Development of reflectance-based crop coef- ficients for corn. Transactions of the ASAE, 32(6), 1891-1900. https://doi.org/10.13031/2013.31240.

Neale, C. M. U., \& Crowther, B. G. (1994). An airborne multispectral video/radiometer remote sensing system: Development and calibration. Remote Sensing of Environment, 49(3), 187-194. https:// doi. org/10.1016/0034-4257(94)90014-0. 
Wang, C., \& Myint, S. W. (2015). A simplified empirical line method of radiometric calibration for small unmanned aircraft systems-based remote sensing. IEEE Journal of Selected Topics in Applied Earth Observations and Remote Sensing, 8(5), 1876-1885. https://doi.org/10.1109/ISTARS.2015.2422716.

Woldt, W., Frew, E., \& Meyer, G. E. (2014). Feeding a hungry world: The potential for unmanned aircraft systems. XRDS Crossroads: The ACM for Students, 4O(3), 24-27. https://doi.org/10.1145/2590599.

Woldt, W., Nowatzki, J., Price, R., Saraswat, D., \& Weckler, P. (2016a). Taking off in new directions with systems. XRDS Crossroads: The ACM for Students, 4O(3), 24-27. https://doi.org/10.1145/2590599.

Woldt, W., Nowatzki, J., Price, R., Saraswat, D., \& Weckler, P. (2016a). Taking off in new directions with unmanned aircraft, special series on unmanned aircraft-Part 1. Resource: Engineering and technol- ogy for a sustainable world (March/April 2016, pp. 16-22). St. Joseph, MI, USA: American Society of Agricultural and Biological Engineers. Retrieved November 28, 2019 from https://www.asabe.org/ ResourcePastIssues.

Woldt, W., Robbins, J., \& Saraswat, D. (2016b). Unmanned Aircraft in Agriculture: Exploring the Oppor- tunities, Special Series on Unmanned Aircraft-Part 3. Resource: Engineering and technology for a sustainable world (July/August 2016, pp. 14-15). St. Joseph, MI, USA: American Society of Agricul- tural and Biological Engineers. Retrieved November 28, 2019 from https://www.asabe. org/ResourcePa stIssues.

Woldt, W., Thomasson, J. A., \& Valasek, J. (2016c). Unmanned Aircraft Systems: All Types and Sizes, Special Series on Unmanned Aircraft-Part 2. Resource: Engineering and technology for a sustain- able world (May/June 2016, pp. 18-19). St. Joseph, MI, USA: American Society of Agricultural and Biological Engineers. Retrieved November 28, 2019 from https://www.asabe.org/ ResourcePastIssues.

Zhang, C., \& Kovacs, J. M. (2012). The application of small unmanned aerial systems for precision agri- culture: A review. Precision Agriculture, 13(6), 693712. https://doi.org/10.1007/s11119-012-9274-5. 